\title{
Short Communication: \\ The potency of lytic bacteriophage isolated from various environments to control the growth of Citrobacter braakii causing urinary tract infection
}

\author{
SHEILAHRUSI, JEPRI AGUNG PRIYANTO, HENI RISMIYATI, IMAN RUSMANA, SRI BUDIARTI ${ }^{*}$ \\ Division of Microbiology, Department of Biology, Faculty of Mathematics and Natural Sciences, Institut Pertanian Bogor. Jl. Agatis, Kampus IPB \\ Dramaga, Bogor 16680, West Java, Indonesia. Tel./fax.: +62-251-8622833, `email: s_budiarti@yahoo.com
}

Manuscript received: 11 October 2021. Revision accepted: 26 November 2021.

\begin{abstract}
Sheilahrusi, Priyanto JA, Rismiyati H, Rusmana I, Budiarti S. 2021. Short Communication: The potency of lytic bacteriophage isolated from various environments to control the growth of Citrobacter braakii causing urinary tract infection. Biodiversitas 22: 5550-5554. Citrobacter braakii is one of the pathogenic bacteria causing urinary tract infection (UTI) in humans. Bacteriophages that are specifically infecting $C$. braakii could be the alternatives to combat antibiotics resistance cases of this bacterium. This study aimed to isolate lytic phages from various environmental samples (tofu factory wastewater, sewage water, rice field water, fishpond water, cattle farm wastewater, and goat farm wastewater), and to analyze their effectivity to reduce UTI-causing $C$. braakii population in vitro. Results exhibited that phages targeting this bacterium were found in goat and cattle farm wastewater and not present in other samples. Two phages, namely FC1 and FC2, had different plaque morphology characteristics. The number of phages in cattle farm wastewater was $2.8 \times 10^{5} \mathrm{PFU} / \mathrm{mL}$ and $1.32 \times 10^{4} \mathrm{PFU} / \mathrm{mL}$ in goat farm wastewater. It was observed that the phages found in these environments also indicate the presence of their host. After $8 \mathrm{~h}$ incubation, FC1 and FC2 phage reduced UTI-causing $C$. braaakii population in vitro from $0.23 \times 10^{8} \mathrm{CFU} / \mathrm{mL}$ to $0.03 \times 10^{8} \mathrm{CFU} / \mathrm{mL}$ and $0.02 \times 10^{8} \mathrm{CFU} / \mathrm{mL}$, respectively. The phages isolated from these two samples can be further developed for the treatment of UTI caused by $C$. braakii and goat and cattle farm wastewater treatment to prevent contaminating other areas.
\end{abstract}

Keywords: Cattle, goat, lytic phage, UTI, wastewater

\section{INTRODUCTION}

Citrobacter braakii Brenner et al. 1993 is an aerobic Gram-negative bacilli that belongs to the Enterobacteriaceae family, and widely distributed in soil, water, food, the urinary and intestinal tract of humans and animals (Sami et al. 2017). This bacterium has been associated with nosocomial infection and one of the common species causing urinary tract infections (UTI) in women and men (Trivedi et al. 2016). However, UTI more frequently occurs in adult women, with a lifetime prevalence of 50-60\% (Medina and Castillo-Pino 2019). Furthermore, this infection can be fatal and higher rate in hospitalized patients (Setyorini et al. 2019). Citrobacter strains are the third most common bacteria causing UTI in hospitalized patients besides Escherichia coli and Klebsiella strains up to $9.4 \%$ of all bacterial isolates obtained (Metri et al. 2013). A previous study through a culture-based approach also revealed that $C$. braakii has been found in urine from UTI-diagnosed children (Christine et al. 2018). Therefore, it is an emergence to find an effective treatment strategy to control the infection cases caused by this bacterium.

Currently, antibiotics-based treatment is commonly used as oral therapy to control $C$. braakii growth. But, unfortunately, this bacterium has been reported to be not sensitive to some antibiotics. Mostly Citrobacter spp. isolated from patients diagnosed with UTI were resistance to ampicillin, co-trimoxazole, norfloxaxin, ciprofloxaxin, gentamicin, netilmicin, amoxiclav, amikacin, cephalexin, cefatoxime, ofloxacin, nitrofurantoin, imipenem, and tobramicin (Metri et al. 2013). The resistance of this bacteria to commonly existing antibiotics is alarming us to develop a new treatment strategy to control this infection. One of the alternative treatments for treating bacterial infections is applying the bacteriophage. Conventionally, bacteriophage-based therapy refers to the use of naturally occurring phages (short call for bacteriophage) to infect and lyse specific bacteria in the infection site. However, biotechnological approaches have further developed new strategies using recombinant phage and purified phage lytic protein for specifically counter to multidrug-resistant bacterial growth (Lin et al. 2017). Therefore, it is clinically important to find the phage from natural sources that could specifically combat $C$. braakii for further development of non-antibiotics-based therapy.

The exploration of phages sources could be started from the existence of their host in the environment or in the pathogen-contaminated samples, since phages and their host coexist in the same environment. For example, lytic phages against pathogenic $E$. coli are found in hospital wastewater (Lingga et al. 2020), and Bacillus pumilus-targeting phages found in Ciapus River-Bogor, Indonesia (Kusmiatun et al. 2015). Nevertheless, the exploration of phages that specifically combats UTI-causing $C$. braakii was not studied yet, especially in Indonesia. Therefore, this study 
investigated the existence of $C$. braakii-infecting phages from various water samples, such as tofu factory wastewater, pool water, sewage water, rice field water, fishpond water, cattle farm wastewater, and goat farm wastewater. This study aimed to isolate lytic phages from various environmental samples and to analyze their effectiveness in reducing UTI-causing $C$. braakii population in vitro.

\section{MATERIALS AND METHODS}

\section{Bacterial isolate source and sample collection}

Citrobacter braakii used in this study was obtained from the urine of UTI-diagnosed children, which has been isolated from our earlier study (Christine et al. 2018). Bacterial isolate was routinely culture in Luria Bertani agar (LA) medium. Various wastewater samples were collected from tofu factory wastewater, sewage water, rice field water (Pesanggrahan, South Jakarta, Indonesia), and from fishpond water (Dramaga, Bogor, West Java, Indonesia). In addition, cattle farm wastewater and goat farm wastewater were collected from cattle farm and goat farm, The Faculty of Animal Science, IPB University, Dramaga-Bogor, Indonesia. All samples were collected in a sterile falcone.

\section{Sample preparation and lytic phage isolation}

The phages were isolated from $4.5 \mathrm{~mL}$ water sample. This sample was mixed with $0.5 \mathrm{~mL}$ Luria Bertani broth medium and $0.5 \mathrm{~mL}$ C. braakii suspension $\left(1 \times 10^{8} \mathrm{CFU} / \mathrm{mL}\right)$. The suspension was then incubated at $37^{\circ} \mathrm{C}$ for $24 \mathrm{~h}$. Then, suspension was centrifuged at $5000 \mathrm{rpm}$ for 20 minutes. The supernatant was collected using a sterilized syringe and filtered by $0.22 \mu \mathrm{m}$ millipore filter. The phages were then isolated using double layer agar method. Then, $100 \mu \mathrm{l}$ of filtrate was mixed with $100 \mu$ of $C$. braakii $\left(1 \times 10^{8}\right.$ $\mathrm{CFU} / \mathrm{mL}$ )-containing $\mathrm{LB}$ medium and incubated at room temperature $\left( \pm 28^{\circ} \mathrm{C}\right)$ for 30 minutes. The suspension was transferred into a new tube containing melted semisolid LA medium and homogenized using vortex. The homogenous suspension was poured into LA medium-containing petri dish and incubated at $37^{\circ} \mathrm{C}$ for $24 \mathrm{~h}$. The plaque formation indicates the presence of phages in the sample.

\section{Phage purification and quantification}

Plaque obtained from the previous step was then collected using Pasteur pipette and transferred into Eppendorf containing $1.5 \mathrm{~mL}$ phosphate buffer saline solution (PBS). This suspension was then homogenized using vortex and left for 5-10 minutes at room temperature $\left( \pm 28^{\circ} \mathrm{C}\right)$. The suspension was then centrifuged at $5000 \mathrm{rpm}$ for 20 minutes. The supernatant was filtered into sterilized tubes using $0.22 \mu \mathrm{m}$ millipore filter, and stored at $4^{\circ} \mathrm{C}$ as phage stock suspension.

Phage quantification was carried out by serially diluted phage stock solution from $10^{-1}$ to $10^{-8}$ in phosphate buffer saline solution (PBS) with $\mathrm{pH}$ 7.4. A total of $100 \mu \mathrm{l}$ of phage suspension from each dilution was mixed with 100 $\mu \mathrm{l}$ of $C$. braakii-containing melted semisolid LA medium (1\% agar) and poured onto LA medium petri dishes. The inoculated plates were incubated at $37^{\circ} \mathrm{C}$ for $24 \mathrm{~h}$. The plaque formed on the plate between 30-300 plaques were counted as plaque forming units per milliliter $(\mathrm{PFU} / \mathrm{mL})$. Then, the titer of plaque was determined using the following formula:

$$
\text { Titer Phage }(\mathrm{PFU} / \mathrm{ml})=\frac{\text { number of plaques per petri dish }}{\text { dilution factor } \times \text { volume phage suspension added }(\mathrm{ml})}
$$

\section{Bacteriolytic assay}

Each phage isolate was assessed to their capability in lysing C. braakii in vitro as per Budiarti et al. (2011). $0.5 \mathrm{~mL}$ of $C$. braakii culture $\left(2.3 \times 10^{7} \mathrm{CFU} / \mathrm{mL}\right)$ was inoculated with $0.5 \mathrm{~mL}$ of each phage suspension, including FC1 $\left(1.3 \times 10^{4}\right.$ $\mathrm{PFU} / \mathrm{mL})$, and FC2 $\left(2.8 \times 10^{5} \mathrm{PFU} / \mathrm{mL}\right)$. Citrobacter braakii culture without phage suspension was served as a control. Each suspension was then inoculated into $50 \mathrm{~mL} \mathrm{LB}$ medium and plated into LA medium at various incubation periods, i.e. $0,2,4,6$, and $8 \mathrm{~h}$. The number of bacterial colonies was determined by the total plate count method.

\section{RESULTS AND DISCUSSION}

\section{The presence of lytic phage in various water samples}

The presence of lytic phages in the sample used in this study was indicated by the plaque formation in the upper layer of $C$. braakii inoculated medium. Of six water samples tested, 2 samples exhibited plaque formation, i.e from goat farm wastewater, and cattle farm wastewater (Figure 1). Plaques found in these samples have different morphological characteristics and diameters (Table 1). Plaque morphology found in goat farm wastewater was clear and irregular-shaped with diameters ranging from 1-3 $\mathrm{mm}$, and coded as FC1, while plaque morphology in cattle farm wastewater was clear and regular-shaped with the diameter ranging from 2-4 mm, and coded as FC2.

\begin{tabular}{|c|c|c|c|}
\hline \multirow{2}{*}{ Sources } & \multirow{2}{*}{ Phage presence* } & \multicolumn{2}{|c|}{ Plaque characteristics } \\
\hline & & Morphology & Diameter (mm) \\
\hline Goat farm wastewater & + & clear, irregular-shaped & $1-3$ \\
\hline Cattle farm wastewater & + & clear, regular-shaped & $2-4$ \\
\hline Fishpond water & - & - & - \\
\hline Sewage water & - & - & - \\
\hline Rice field water & - & - & - \\
\hline Tofu factory wastewater & - & - & - \\
\hline
\end{tabular}

Table 1. The presence of lytic plaque in various samples and its characteristics 


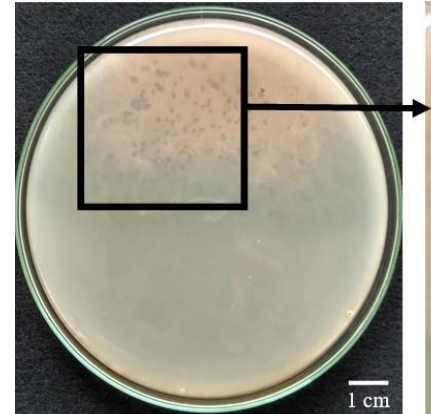

A

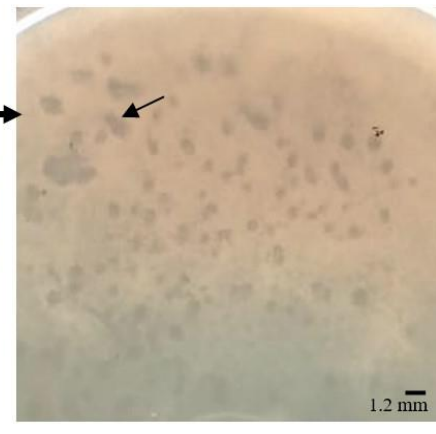

B

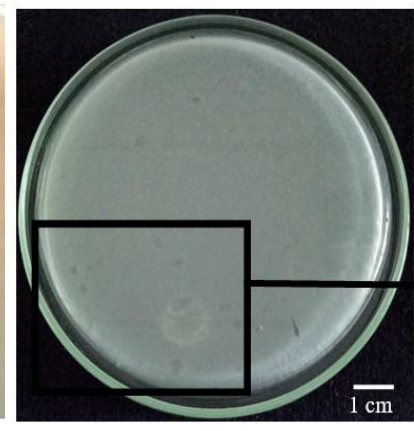

C

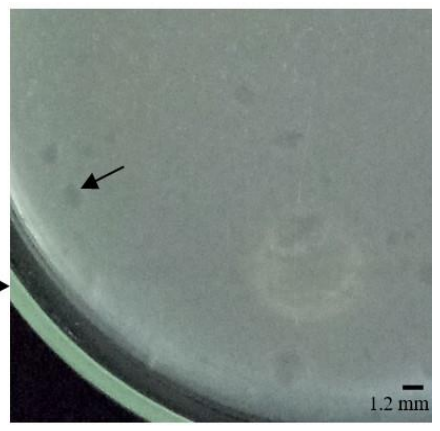

$\mathbf{D}$

Figure 1. Plaque morphology in Luria Bertani Double Layer Agar isolated from: A. goat farm wastewater, B. zoom of A plate, C. cattle farm wastewater, D. zoom of C plate. Black arrow shows plaque morphology

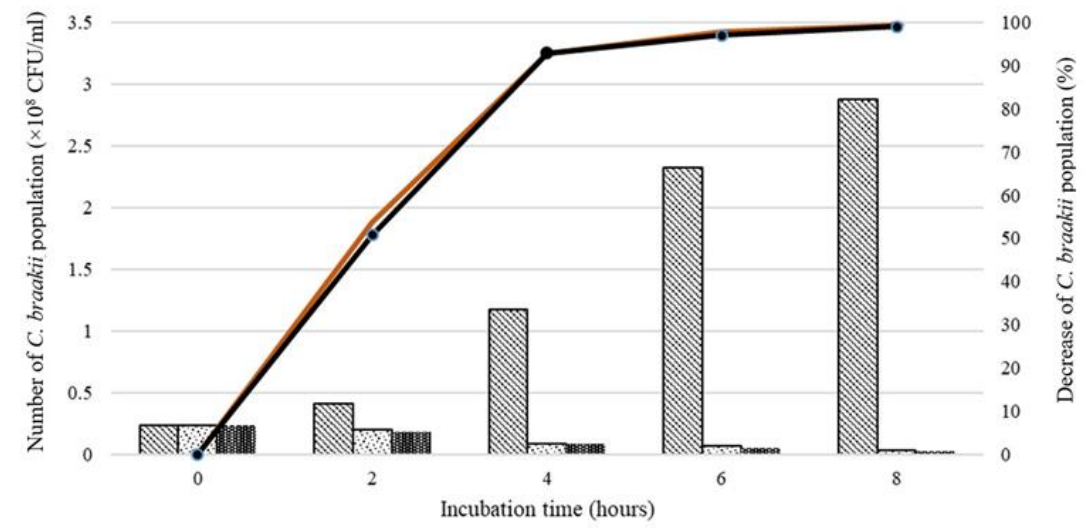

Figure 2. Citrobacter braakii population after inoculated with purified FC1 ( decreased population after treated with lytic phages FC1 $(\mapsto)$ and FC2 $(\boldsymbol{-}-\mathbf{-})$ after 8 hours

The number of lytic-phage present in goat and cattle farm wastewater

Results showed that the number of phages present in cattle farm wastewater was higher than goat wastewater. The plaques number in cattle farm wastewater and goat wastewater were $2.8 \times 10^{5} \mathrm{PFU} / \mathrm{mL}$ and $1.32 \times 10^{4} \mathrm{PFU} / \mathrm{mL}$, respectively.

\section{Bacteriolytic activities of isolated phages against Citrobacter braakii}

Phage isolated from goat farm wastewater (FC1) and cattle farm wastewater (FC2) decreased the number of $C$. braakii population in vitro. C. braakii population infected with phage FC1 and FC2 gradually decreased following the incubation time. After $8 \mathrm{~h}$ infected with $\mathrm{FC} 1$ and FC2, $C$. brakii population $\left(0.23 \times 10^{8} \mathrm{CFU} / \mathrm{mL}\right)$ decreased to $0.03 \times 10^{8} \mathrm{CFU} / \mathrm{mL}$ and $0.02 \times 10^{8} \mathrm{CFU} / \mathrm{mL}$. In contrast, $C$. braakii population in control treatment was gradually increased from $2.3 \times 10^{7} \mathrm{CFU} / \mathrm{mL}$ at $0 \mathrm{~h}$ incubation time to $2.88 \times 10^{8} \mathrm{CFU} / \mathrm{mL}$ after $8 \mathrm{~h}$ incubation. These two lytic phages effectively reduced C. braakii population up to $99 \%$ for FC1 and $99.3 \%$ for FC2 (Figure 2).

\section{Discussion}

Lytic phages infecting UTI-causing $C$. braakii, named as FC1 and FC2, have been isolated from two different wastewater sources, including from goat farm wastewater and cattle farm wastewater, respectively. The presence of these phages in the water samples is indicated by the clear plaque formation. The plaque formed because of the ability of phage to infect and lysis $C$. braakii cells specifically. Due to the specific phages coexisting with their specific host, these two environments also might be colonized by UTI-causing $C$. braakii. In contrast, no phage was found in other samples, such as tofu factory wastewater, pool water, sewage water, rice field water, indicating that UTI-causing C. braakii was not exist in these environments. In the earlier studies, phages infecting pathogenic bacteria were commonly found in clinical samples where their host was suspected to live in the same environment, such as hospital wastewater (Lingga et al. 2020), and the human body (Brown et al. 2016). Nevertheless, pathogenic bacteriainfecting phages also have been found in non-clinical samples, i.e, wastewater treatment plant (Khairnar et al. 2014), fishpond water (Jin et al. 2012), sewage (Jia et al. 2020), and river (Bhetwal et al. 2017). This is the first report that phages targeting UTI-causing $C$. braakii were 
found in goat and cattle farm wastewater, as well as suggesting that $C$. braakii also exist in these environments. Therefore, good management of wastewater from these environments is necessary to prevent the spread of this pathogenic bacterium to other environments.

The number of phages present in cattle farm wastewater was higher than goat wastewater with plaques number of $2.8 \times 10^{5} \mathrm{PFU} / \mathrm{mL}$ and $1.32 \times 10^{4} \mathrm{PFU} / \mathrm{mL}$, respectively. These phage numbers may be correlated with the number of hosts in wastewater sources. The results also indicated that these environments were favorable for the growth of phages and their hosts. As these areas were contaminated by cattle and goat fesses, and provide high nutrition from animal feed residues. C. braakii may originate from cattle and goat. As reported by previous studies, Citrobacter sp. asymptomatically associated with intestinal tract of ruminants (Seshadri et al. 2018) and also found as microflora in raw cow milk (Pukancikova et al. 2016).

FC1 and FC2 phage exhibited bacteriolytic activity and decreased UTI-causing C. braakii population in vitro up to $99 \%$ and $99.3 \%$, respectively, after $24 \mathrm{~h}$ incubation. $C$. brakii culture infected with FC1 and FC2 phage contained $0.03 \times 10^{8} \mathrm{CFU} / \mathrm{mL}$ and $0.02 \times 10^{8} \mathrm{CFU} / \mathrm{mL}$, significantly decreased from the early bacterial cell density $\left(2.88 \times 10^{8}\right.$ $\mathrm{CFU} / \mathrm{mL}$ ). Supporting these results, FU3 phage from Cisadane river also was able to reduce $\left(10^{4} \mathrm{CFU} / \mathrm{mL}\right)$ uropathogenic-Escherichia coli. (UPEC) after $25 \mathrm{~h}$ incubation (Sufa et al. 2018). The decrease of the host population is probably due to phage lytic enzyme production and activity. This enzyme was commonly known as lysin, an antimicrobial molecule produced by phage, which can degrade peptidoglycan of bacterial host and initiate cell lysis (Miguel et al. 2020). Supporting the present study, several earlier studies also found that phages originated from various animal farm wastes potentially have bacteriolytic activities against specific bacteria. Phage from goat farm waste was able to reduce shiga-toxin producing E. coli population (Lennon et al. 2020). Phage isolated from wastewater collection tanks of various animal species also showed bacteriolytic activities against most common bacteria, including E. coli and Bacillus subtilis (Shukla and Hirpurkar 2011). Phage originated from fecal cattle sample was able to infect E. coli O157:H7 (Hallewell et al. 2014). In addition, phage isolated from feedlot cattle also reduced $E$. coli $\mathrm{O} 157: \mathrm{H} 7$ population in cattle digestive tracts (Callaway et al. 2008). Fortunately, these lytic phages FC1 and FC2 specific to $C$. braakii may provide an alternative to antibiotics for the treatment of UTI caused by this bacterium. This phage can also be a biocontrol agent in goat and cattle farm wastewater treatment before releasing to other areas.

\section{ACKNOWLEDGEMENTS}

All authors thanks to Division of Microbiology, Department of Biology, Faculty of Mathematics and Natural Sciences, IPB University, Bogor, Indonesia for facilitating this research.

\section{REFERENCES}

Bhetwal A, Maharjan A, Shakya S, Satyal D, Ghimire S, Khanal PR, Parajuli NP. 2017. Isolation of potential phages against multidrugresistant bacterial isolates: promising agents in the rivers of Kathmandu, Nepal. Biomed Res Intl 2017: 1-10. DOI: $10.1155 / 2017 / 3723254$.

Brown TL, Petrovski S, Dyson ZA, Seviour R, Tucci J. 2016. The formulation of bacteriophage in a semi solid preparation for control of Propionibacterium acnes growth. Plos One 11 (13): e0151184. DOI: 10.1371/journal.pone.0151184.

Budiarti S, Pratiwi RH, Rusmana I. 2011. Infectivity of lytic phage to enteropathogenic Escherichia coli from diarrheal patients in Indonesia. J US-China Med Sci 8: 273-282.

Callaway TR, Edrington TS, Brabban AD, Anderson RC, Rossman ML, Engler MJ, Carr MA, Genovese KJ, Keen JE, Looper ML, Kutter EM, Nisbet DJ. 2008. Bacteriophage isolated from feedlot cattle can reduce Escherichia coli o157:h7 populations in ruminant gastrointestinal tracts. Foodborne Pathog Dis 5 (2): 183-191. DOI: 10.1089/fpd.2007.0057

Christine G, Budiarti S, Astuti RI. 2018. Diversity of urinary tract infection bacteria in children in Indonesia based on metagenomic approach. Biodiversitas 19: 1375-1381. DOI: 10.13057/biodiv/d190425

Hallewell J, Niu YD, Munns K, McAllister TA, Johnson RP, Ackermann HW, Thomas JE, Stanford K. 2014. Differing populations of endemic bacteriophages in cattle shedding high and low numbers of Escherichia coli O157:H7 bacteria in feces. Appl Environ Microbiol 80 (13): 3819-3825. DOI: 10.1128/AEM.00708-14.

Jia K, Yang N, Zhang X, Cai R, Zhang Y, Tian J, Raza SHA, Kang Y, Qian A, Li Y, Sun W, Shen J, Yao J, Shan X, Zhang L, Wang G. 2020. Genomic, morphological and functional characterization of virulent bacteriophage IME-JL8 targeting Citrobacter freundii. Front Microbiol 11: 1-12. DOI: 10.3389/fmicb.2020.585261

Jin J, Li ZJ, Wang SW, Huang DH, Li YH, M YY, Wang J, Liu F, Chen XD, Li GX, Wang XT, Wang ZQ, Zhao GQ. 2012. Isolation and characterization of ZZ1, a novel lytic phage that infects Acinetobacter baumannii clinical isolates. BMC Microbiol 12 (156): 1-8. DOI: 10.1186/1471-2180-12-156.

Khairnar K, Pal P, Chandekar RH, Paunikar WN. 2014. Isolation and characterization of bacteriophages infecting nocardioforms in wastewater treatment plant. Biotechnol Res Intl 2014: 1-5. DOI: $10.1155 / 2014 / 151952$.

Kusmiatun A, Rusmana I, Budiarti S. 2015. Characterization of bacteriophage specific to Bacillus pumilus from Ciapus River in Bogor, West Java, Indonesia. Hayati J Biosci 22: 27-33. DOI: 10.4308/hjb.22.1.27.

Lennon M, Liao YT, Slavador A, Lauzon CR, Wu VC. 2020. Bacteriophages specific to Shiga toxin-producing Escherichia coli exist in goat feces and associated environments on an organic produce farm in Northern California, USA. Plos One 15 (16): 1-16. DOI: 10.1371/journal.pone.0234438.

Lin DM, Koskella B, Lin HC. 2017. Phage therapy: an alternative to antibiotics in the age of multi-drug resistance. World J Gastrointest Pharmacol Theurapetics 8: 162-173. DOI: 10.4292/wjgptv8.i3.162.

Lingga R, Budiarti S, Rusmana I, Wahyudi AT. 2020. Isolation, characterization and efficacy of lytic bacteriophages against pathogenic Escherichia coli from hospital liquid waste. Biodiversitas 21: 3234-3241. DOI: 10.13057/biodiv/d210745.

Medina M, Castillo-Pino E. 2019. An introduction to the epidemiology and burden of urinary tract infections. Theurapeut Advin Urol 11: 3-7. DOI: $10.1177 / 1756287219832172$.

Metri BC, Jyothi P, Peerapur BV. 2013. Antibiotic resistance in Citrobacter spp. isolated from urinary tract infection. Urol Annals 5: 312-313. DOI: 10.4103/0974-7796.120295.

Miguel TD, Rama JLR, Sieiro C, Sanchez S, Villa TG. 2020. Bacteriophages and lysins as possible alternatives to treat antibioticresistant urinary tract infections. Antibiotics 9 (8): 1-12. DOI: 10.3390/antibiotics9080466.

Pukancikova L, Lipnicanova S, Kacaniova M, Chmelova D, Ondrejovic M. 2016. Natural microflora of raw cow milk and their enzymatic spoilage potential. Nova Biotech et Chimica 15 (2): 142-155. DOI: 10.1515/nbec-2016-0015. 
Sami H, Sultan A, Rizvi M, Khan F, Ahmad S, Shukla I, Khan HM. 2017. Citrobacter as a uropathogen, its prevalence and antibiotics susceptibility pattern. Virol J 4: 23-26. DOI: 10.4103/23483334.196037.

Seshadri R, Leahy SC, Attwood GT, The KH, Lambie SC, Cookson AL, Paez-Espino D, Hungate 1000 project collaborators, Perry R, Henderson G, Creevey CJ, Terrapon N, Lapebie P, Drula E, Lombard V, Rubin E, Kyrpides NC, Henrissat B, Woyke T, Ivanova NN, Kelly WJ. 2018. Cultivation and sequencing of rumen microbiome members from the Hungate1000 collection. Nat Biotechnol 36 (4): 359-367. DOI: $10.1038 /$ nbt. 4110 .

Setyorini H, Tjempakasari A, Mardiana N. 2019. Risk factors for urinary tract infection in hospitalized patients. Biomol Health Sci J 2: 4-8. DOI: $10.20473 /$ bhsjv2i1.11549.
Shukla S, Hirpurkar D. 2011. Recovery status of bacteriophages of different livestock farms of Veterinary College, Adhartal, Jabalpur, India. Vet World 4 (3): 117-119. DOI: 10.5455/vetworld.2011.117119.

Sufa HI, Budarti S, Rusmana I. 2018. Diversity of uropathogenic Escherichia coli lytic phage from Cisadane River, West Java, Indonesia based on morphology and protein molecular weight characteristics. Biodiversitas 19 (6): 2359-2364. DOI: 10.13057/biodiv/d190646.

Trivedi MK, Branton A, Trivedi D, Nayak G, Mondal SC, Jana S. 2015. Phenotyping and 16S rDNA analysis after biofield treatment on Citrobacter braakii: A urinary pathogen. J Clin Med Genomics 3: 18. DOI: $10.4172 / 2472-128 X .1000129$. 